\title{
Perfil fermentativo e composição bromatológica de silagens de sorgo em função da adubação nitrogenada
}

\author{
Fermentation characteristics and chemical composition of sorghum silage in function of \\ nitrogen fertilization
}

\author{
MACEDO, Carlos Henrique Oliveira ${ }^{1 *}$; ANDRADE, Albericio Pereira de ${ }^{1}$; SANTOS, \\ Edson Mauro ${ }^{1}$; SILVA, Divan Soares da ${ }^{1}$; SILVA, Thiago Carvalho da ${ }^{2}$; EDVAN, \\ Ricardo Loiola ${ }^{3}$
}

\footnotetext{
${ }^{1}$ Universidade Federal da Paraíba,Centro de Ciência Agrárias, Departamento de Zootecnia, Areia, Paraíba, Brasil.

${ }^{2}$ Universidade Federal de Viçosa,Centro de Ciência Agrárias, Departamento de Zootecnia, Viçosa, Minas Gerais, Brasil.

${ }^{3}$ Universidade Federal do Ceará, Centro de Ciência Agrárias, Departamento de Zootecnia, Fortaleza, Ceará, Brasil.

*Endereço para correspondência: chompvhro@hotmail.com
}

\section{RESUMO}

Dois experimentos foram conduzidos com o objetivo de avaliar o perfil fermentativo e a composição bromatológica de silagens de sorgo. No experimento 1, avaliou-se o perfil fermentativo do sorgo em resposta à adubação nitrogenada, em delineamento inteiramente casualizado, em parcela subdividida 5 × 6 (cinco doses de nitrogênio e seis períodos de abertura). As doses de adubação nitrogenada foram: $0 ; 50 ; 100 ; 150$ e $200 \mathrm{~kg} / \mathrm{ha}$ e os períodos de abertura foram: $1 ; 3 ; 7 ; 14 ; 28$ e 49 dias. No experimento 2 avaliaram-se as variações nos constituintes bromatológicos do sorgo. O delineamento experimental utilizado foi em blocos casualizados com cinco repetições, e os tratamentos tiveram os mesmos níveis de adubação do experimento 1 . Os teores de matéria seca aumentaram linearmente com as doses de nitrogênio e com o período de fermentação. $\mathrm{O}$ pH aumentou linearmente em função da adubação nitrogenada e apresentou resposta quadrática em função do período de fermentação. Os valores de $\mathrm{N}-\mathrm{NH}_{3}$ apresentaram resposta quadrática, tanto a doses de nitrogênio, quanto dos dias de abertura. A matéria orgânica aumentou linearmente e a matéria mineral reduziu. Lignina respondeu de forma linear crescente ao incremento da adubação nitrogenada. Os teores de hemicelulose reduziram linearmente. Os valores de matéria seca, $\mathrm{pH}$ e amônia demonstraram eficácia no processo fermentativo da silagem, independente da quantidade de nitrogênio utilizado. A utilização da adubação é uma prática interessante, pois aumenta a produtividade da planta sem alterar a composição bromatológica da silagem.

Palavras-chave: amônia, fibra, $\mathrm{pH}$, proteína

\section{SUMMARY}

Two experiments were conducted to evaluate the fermentation characteristics and chemical composition of sorghum silage. In the first experiment the fermentative profile of sorghum silages in response to nitrogen fertilization was evaluated using a completely randomized design, in split-plot scheme with five doses of nitrogen (in the plot) and six opening times (in the subplot). The nitrogen levels were $0 ; 50 ; 100 ; 150$ and $200 \mathrm{~kg} / \mathrm{ha}$ and the opening times were: $1 ; 3 ; 7 ; 14$; 28and 49 days after ensiling. In the second experiment the variations in the chemical composition of sorghum silages was evaluated. The experimental design was randomized blocks with five repetitions, and the treatments consisted on the same levels of fertilization of first experiment. Dry matter increased linearly with the nitrogen and the fermentation period. The $\mathrm{pH}$ increased linearly as a function of nitrogen and showed a quadratic response as a function of fermentation period. The $\mathrm{N}-\mathrm{NH}_{3}$ values showed a quadratic response both to nitrogen as for the 
opening day. Organic matter increased linearly and mineral matter decreased. Lignin responded linearly to increasing nitrogen fertilization. The hemicellulose decreased linearly. The dry matter, $\mathrm{pH}$ and ammonia values show efficacy in the silage fermentation process independent of nitrogen level used. The use of fertilizer is an interesting practice, which increases plant productivity without changing the chemical composition of the silage. Nevertheless, for the most economic treatment, is indicated the use of $150 \mathrm{~kg}$ of nitrogen per hectare.

Keywords: ammonia, fibrin, $\mathrm{pH}$, protein

\section{INTRODUÇÃO}

Nas regiões semiáridas, a produção de alimentos para o rebanho constitui, provavelmente, o maior desafio, devido à variabilidade e incertezas climáticas, a tornar a cultura de forrageiras de clima temperado elou tropicais uma atividade de alto risco. Assim, os problemas decorrentes da estacionalidade de produção no semiárido podem ser minimizados pelo armazenamento do alimento na forma de silagem.

O milho e o sorgo apresentam-se como as plantas mais adaptadas ao processo de ensilagem por suas facilidades de cultivo e alto rendimento, além de não haver necessidade de aplicação de aditivos para estimular a fermentação. Não obstante, consideradas todas as etapas do processo produtivo, desde o cultivo até a oferta de volumosos aos animais, o custo total médio do sorgo é inferior ao de culturas perenes, como cana-de-açúcar e capim-tanzânia, segundo Nussio et al. (2006) e Barros et al. (2010).

Dentre as forrageiras anuais o sorgo pode tolerar considerável variação na fertilidade do solo e no balanço de vários nutrientes, porém, a produção e a eficiência da planta são afetadas por esses fatores em conjunto com os efeitos climáticos, o que pode refletir na produção e na qualidade nutricional da forragem.

Entre os macronutrientes, o nitrogênio possui papel fundamental para a nutrição das plantas, por ser constituinte essencial das proteínas e interferir diretamente no processo fotossintético, decorrente de sua participação na molécula de clorofila (ANDRADE et al. 2000).

Segundo Martins (2003), a qualidade de qualquer alimento é dada pelo valor nutritivo representado pela sua composição química, digestibilidade dos seus constituintes, consumo voluntário e desempenho animal. Além do valor nutritivo, a capacidade de conservação é outra característica que determina a adequação de uma cultura à ensilagem. De maneira geral, o termo "qualidade de silagem" está relacionado à eficácia do processo fermentativo para conservar a massa ensilada. Com base no exposto, objetivou-se avaliar o perfil fermentativo e a composição bromatológica de silagens de sorgo em resposta à adubação nitrogenada.

\section{MATERIAL E MÉTODOS}

Os experimentos foram executados na Estação Experimental do Instituto Nacional do Semiárido (INSA), no município de Campina Grande - PB. As variáveis climáticas estão apresentadas na Tabela 1.

Devido às inclinações de relevo do local de estudo, o delineamento experimental utilizado foi em blocos casualizados com cinco repetições. Os tratamentos experimentais foram doses crescentes de adubação nitrogenada: $0 ; 50 ; 100$; 150 e $200 \mathrm{~kg} / \mathrm{ha}$, na forma de sulfato de amônio. 
Rev. Bras. Saúde Prod. Anim., Salvador, v.13, n.2, p.371-382 abr./jun., 2012 http://www.rbspa.ufba.br ISSN 15199940

Tabelas 1. Médias climáticas mensais registradas na estação meteorológica no Instituto Nacional do Semiárido

\begin{tabular}{lcccccc}
\hline Variáveis climáticas & Fevereiro & Março & Abril & Maio & Junho & Julho \\
\hline Precipitação $(\mathrm{mm})$ & 0,7 & 407,3 & 56,9 & 83,4 & 47,5 & 96,3 \\
Temperatura $\left({ }^{\circ} \mathrm{C}\right)$ & 27,6 & 26,3 & 24,6 & 23,9 & 22,3 & 21,6 \\
\hline
\end{tabular}

O sorgo utilizado foi o híbrido BR 601, com característica forrageira e porte alto $(3,00 \mathrm{~m})$. A semeadura da gramínea foi realizada em março de 2008 , em área não calcareada, em parcelas de $20 \mathrm{~m}^{2}(5,0 \mathrm{x}$ 4,0m), com um metro de espaçamento entre linhas, que estabeleceram com o desbaste, 14 plantas por metro linear. Antes da adubação, amostras de solo da camada de $0-20 \mathrm{~cm}$ foram retiradas para determinação das características químicas (Tabela 2).

Tabela 2. Análise química do solo da área do experimento localizado na estação experimental do Instituo Nacional do Semiárido

\begin{tabular}{lcccccccc}
\hline $\mathrm{pH}$ & $\mathrm{P}$ & $\mathrm{K}+$ & $\mathrm{H}^{+}+\mathrm{Al}^{+3}$ & $\mathrm{Al}^{+3}$ & $\mathrm{Ca}^{+2}$ & $\mathrm{Mg}^{+2}$ & $\mathrm{CTC}$ & M.O. \\
\hline $\mathrm{H}_{2} \mathrm{O}$ & $\mathrm{mg} / \mathrm{dm}^{3}$ & \multicolumn{3}{c}{$\mathrm{cmolc}^{2} \mathrm{dm}^{3}$} & & $\mathrm{~g} / \mathrm{kg}$ \\
\hline 5,8 & 13,61 & 167,50 & 3,63 & 0,10 & 2,10 & 1,00 & 7,54 & 8,62 \\
\hline
\end{tabular}

A adubação nitrogenada foi realizada em dose única manualmente e em área total de cada parcela, quando a planta atingiu $30 \mathrm{~cm}$ de altura. Assim, as parcelas receberam $0 ; 50 ; 100 ; 150 \mathrm{e}$ $200 \mathrm{~kg} / \mathrm{ha}$ de nitrogênio com cinco repetições por tratamento.

Aos 119 dias após o plantio, quando a planta atingiu o estádio de grãos farináceos duros, efetuou-se a colheita dos mesmos. O sorgo de todas as parcelas foi cortado rente ao solo com cutelos e colhido manualmente, levado à casa de apoio e, em seguida, picado em máquina forrageira estacionária.

$\mathrm{O}$ delineamento utilizado para a avaliação do perfil fermentativo foi inteiramente casualizado, com esquema fatorial 5 × 6 (cinco doses de nitrogênio e seis períodos de fermentação), com três repetições. As doses de nitrogênio foram $0 ; 50 ; 100 ; 150$ e $200 \mathrm{~kg} /$ ha de sulfato de amônio e os períodos de fermentação: um; três; sete; 14; 28 e 49 dias após ensilagem.

O material foi ensilado em silos de PVC, com $10 \mathrm{~cm}$ de diâmetro e $40 \mathrm{~cm}$ de altura. A compactação do material foi realizada com soquetes de madeira, colocando-se aproximadamente $2 \mathrm{~kg}$ de forragem fresca por silo, e buscou-se densidade média de $550 \mathrm{~kg} / \mathrm{m}^{3}$. A cada dia de abertura, amostras das silagens foram colhidas para determinação de $\mathrm{pH}$ e nitrogênio amoniacal, segundo Bolsen et al. (1992). Em 100mL de água destilada foram adicionados $25 \mathrm{~g}$ de silagem, que permaneceram em repouso por uma hora, para leitura de $\mathrm{pH}$, mediante a utilização de um potenciômetro. Em $200 \mathrm{~mL}$ de solução de $\mathrm{H}_{2} \mathrm{SO}_{4}$ (PA), foram colocados $25 \mathrm{~g}$ de silagem, que permaneceram em repouso na geladeira por 48 horas. Após filtragem em papel de filtro, o filtrado foi congelado para posterior determinação de nitrogênio amoniacal. Foram colhidos 
aproximadamente $500 \mathrm{~g}$ de amostra de silagem de cada silo. Essas amostras foram pré-secas em estufa de ventilação forçada a $65^{\circ} \mathrm{C}$, nas quais se realizou as determinações de matéria pré-seca (ASA). A matéria seca (ASE) foi determinada por meio de secagem em estufa a $105^{\circ} \mathrm{C}$ durante 24 horas.

Os dados obtidos foram submetidos à análise de variância e regressão, e ajustados ao modelo de superfície de resposta, com duas variáveis independentes (doses de nitrogênio e período de fermentação). Tomou-se como critério para escolha dos modelos os valores dos coeficientes de determinação e a significância dos parâmetros da regressão, testados pelo teste $\mathrm{t}$, ao nível de $5 \%$ de significância.

Para a avaliação da composição bromatológica, o delineamento experimental utilizado foi em blocos casualizados, com cinco tratamentos e cinco repetições. Os tratamentos experimentais foram doses crescentes de adubação nitrogenada (sulfato de amônio): $0 ; 50 ; 100 ; 150$ e $200 \mathrm{~kg} / \mathrm{ha}$.

$\mathrm{O}$ material foi ensilado em baldes plásticos, com capacidade para $15 \mathrm{~L}$, dotados de válvula de bunsen, para escape dos gases. A compactação do material nos baldes foi realizada por meio de pisoteio de um homem, que utilizou em média $5 \mathrm{~kg}$ de forragem fresca por balde e mesma densidade do experimento 1. Os silos foram abertos 49 dias após a ensilagem.

Foram colhidos aproximadamente $500 \mathrm{~g}$ de amostra de silagem de cada silo e das plantas antes da ensilagem. As amostras foram pré-secas em estufa com ventilação forçada a $65^{\circ} \mathrm{C}$, nas quais se determinaram teores de matéria seca (MS), proteína bruta (PB) e fibra em detergente neutro (FDN). A matéria seca foi determinada por meio de secagem em estufa a $105^{\circ} \mathrm{C}$ durante 24 horas, PB pelo método de Kjeldahl e
FDN pelo método Ankon, e matéria orgânica (MO) e material mineral (MM), segundo Silva \& Queiroz (2002).

Os dados obtidos foram submetidos à análise de variância e regressão. $\mathrm{O}$ efeito das doses de adubo foi avaliado por meio de análise de regressão, tomando-se como critério para escolha dos modelos, os valores dos coeficientes de determinação e a significância dos parâmetros da regressão, testados pelo teste t, ao nível de $5 \%$ de significância.

\section{RESULTADOS E DISCUSSÃO}

Verificou-se aumento linear $(\mathrm{P}<0,05)$ dos teores de MS com as doses de nitrogênio e com o período de fermentação (Figura 1), respectivamente. Esse aumento em função da adubação nitrogenada no teor de MS pode estar associado ao incremento do $\mathrm{N}$ à planta, tendo em vista que este atua diretamente no aumento da produção de biomassa total, em que ocorre principalmente intensificação no processo de alongamento do colmo e diminuição progressiva na proporção de folhas, com consequente redução do conteúdo celular e do valor nutritivo da planta, bem como pela participação da panícula na produção de matéria natural.

Oliveira et al. (2010), ao trabalharem com os híbridos de sorgo BR 700, $1 \mathrm{~F}$ 305, 0369267 e 0369255 e três níveis de $\mathrm{N}$ na forma de sulfato de amônio $(0 ; \quad 60$ e $120 \mathrm{~kg} / \mathrm{ha})$ observaram variações de 9,1 a $15,5 \mathrm{~kg} / \mathrm{ha}$ na produção de matéria seca do menor para o maior nível de adubação, com destaque para o híbrido 0369255 adubado com $120 \mathrm{~kg} / \mathrm{ha}$ de N. No entanto, essa resposta positiva da MS em função dos dias de abertura não era esperada, devido às fermentações secundárias, que ocasionam perdas 
Rev. Bras. Saúde Prod. Anim., Salvador, v.13, n.2, p.371-382 abr./jun., 2012 http://www.rbspa.ufba.br ISSN 15199940

inevitáveis de nutrientes durante $\mathrm{o}$ processo fermentativo. Não obstante, esse resultado pode estar associado à produção de efluentes do material ensilado.

Os valores médios de $36,32 \%$ de MS nos cinco níveis de adubação, ao final do período de fermentação, são superiores aos encontrados por Ribeiro et al. (2007), o qual obteve $32,09 \%$ aos 56 dias de abertura dos silos. Os mesmos autores não observaram alterações nos valores de MS das silagens nos diferentes períodos de abertura (zero a 56 dias), isto é, a matéria seca se manteve estável.

Verifica-se no presente estudo, o aumento linear do $\mathrm{pH} \quad(\mathrm{P}<0,05)$ em função da adubação nitrogenada e uma consequente resposta quadrática $(\mathrm{P}<0,05)$ em função do período de fermentação (Figura 2).

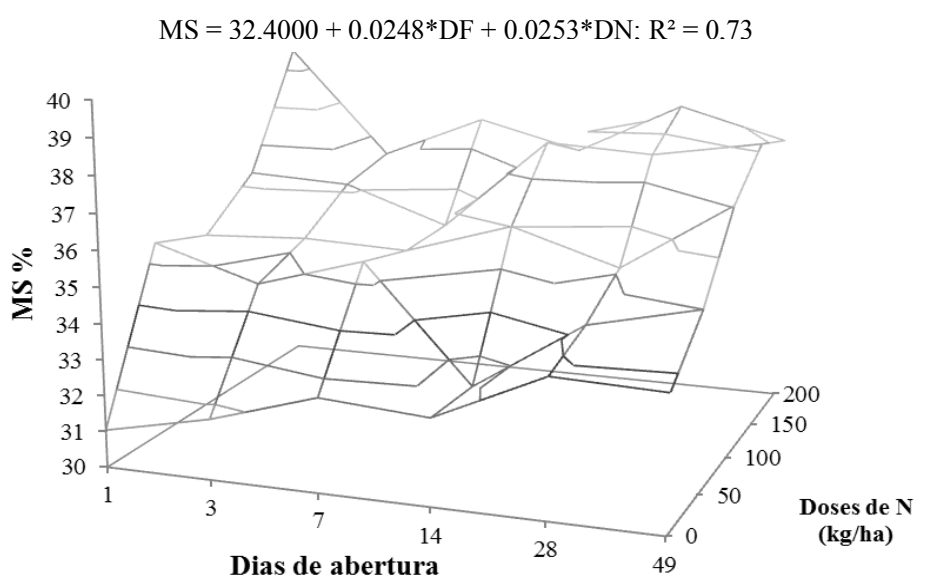

Figura 1. Variação no percentual de matéria seca (MS) de sorgo em função de níveis de adubação nitrogenada (DN) e dias de fermentação (DF)

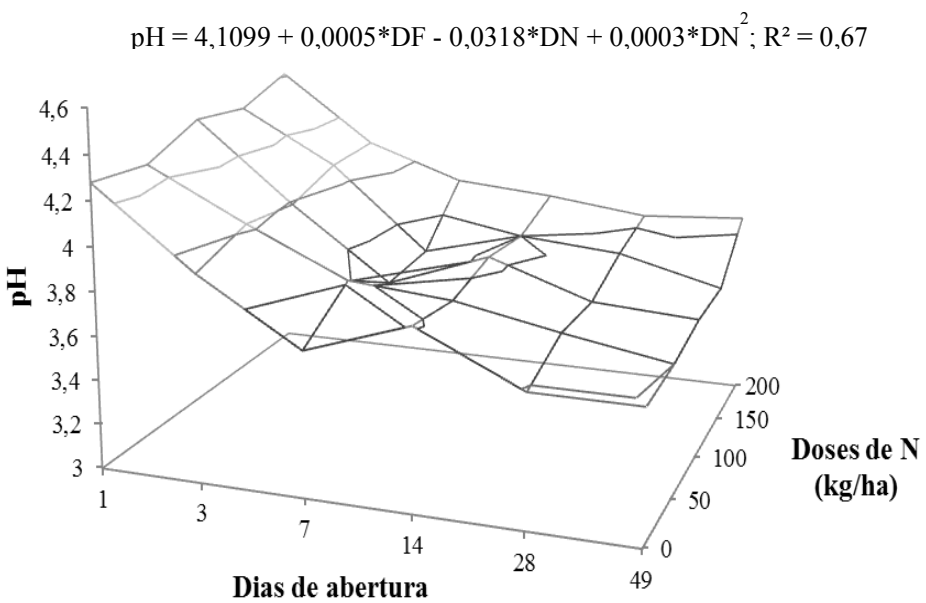

Figura 2. Variação no pH de sorgo em função de níveis de adubação nitrogenada (DN) e dias de fermentação (DF) 
Rev. Bras. Saúde Prod. Anim., Salvador, v.13, n.2, p.371-382 abr./jun., 2012 http://www.rbspa.ufba.br ISSN 15199940

No entanto, ao sétimo dia de abertura o material já havia estabilizado, com $\mathrm{pH}$ em média de 3,74 (Tabela 3), e consequente redução aos 49 dias de abertura $(3,66)$. Essa estabilização pode estar associada às características adequadas do material ensilado, o que permitiu fermentação satisfatória, devido à maior população de bactérias láticas e aumento da produção de ácido lático com natural acidificação do meio. McDonald et al. (1991) classificaram uma silagem de boa qualidade, quando a massa ensilada apresentava valores de $\mathrm{pH}$ entre 3,8 e 4,2. Contudo, verifica-se que a faixa de $\mathrm{pH}$ encontrada, no presente experimento, está dentro do padrão de fermentação de boa qualidade.

Tabela 3. Teores médios de matéria seca (MS), pH e nitrogênio amoniacal $\left(\mathrm{N}-\mathrm{NH}_{3}\right)$, das silagens de sorgo em função de doses de nitrogênio $(\mathrm{X})$ e períodos de fermentação $(Z)$

\begin{tabular}{|c|c|c|c|c|c|c|c|}
\hline \multirow{2}{*}{ Adubação } & \multicolumn{6}{|c|}{ Dias de Abertura } & \multirow{2}{*}{ Média } \\
\hline & 1 & 3 & 7 & 14 & 28 & 49 & \\
\hline \multicolumn{8}{|c|}{ MS (\%) } \\
\hline 0 & 31,05 & 31,69 & 32,61 & 32,40 & 33,81 & 33,71 & 32,55 \\
\hline 50 & 35,51 & 34,61 & 35,49 & 32,32 & 34,30 & 35,00 & 34,54 \\
\hline 100 & 35,04 & 35,19 & 35,08 & 36,01 & 35,09 & 37,05 & 35,58 \\
\hline 150 & 36,28 & 36,14 & 35,13 & 37,79 & 37,64 & 38,14 & 36,85 \\
\hline 200 & 39,54 & 36,49 & 37,74 & 36,99 & 38,50 & 37,68 & 37,83 \\
\hline Média Geral & 35,48 & 34,82 & 35,21 & 35,10 & 35,87 & 36,32 & \\
\hline \multicolumn{8}{|c|}{$\mathrm{pH}$} \\
\hline 0 & 4,28 & 3,93 & 3,65 & 3,81 & 3,59 & 3,59 & 3,81 \\
\hline 50 & 4,25 & 4,02 & 3,81 & 3,77 & 3,68 & 3,60 & 3,86 \\
\hline 100 & 4,36 & 3,99 & 3,66 & 3,83 & 3,67 & 3,64 & 3,86 \\
\hline 150 & 4,32 & 4,07 & 3,68 & 3,80 & 3,76 & 3,64 & 3,88 \\
\hline 200 & 4,41 & 4,08 & 3,92 & 3,88 & 3,82 & 3,85 & 3,99 \\
\hline Média Geral & 4,32 & 4,02 & 3,74 & 3,82 & 3,70 & 3,66 & \\
\hline \multicolumn{8}{|c|}{$\mathrm{N}-\mathrm{NH}_{3}(\% \mathrm{MS})$} \\
\hline 0 & 0,026 & 0,028 & 0,026 & 0,038 & 0,050 & 0,016 & 0,031 \\
\hline 50 & 0,024 & 0,027 & 0,027 & 0,040 & 0,021 & 0,015 & 0,026 \\
\hline 100 & 0,031 & 0,014 & 0,016 & 0,034 & 0,021 & 0,015 & 0,022 \\
\hline 150 & 0,032 & 0,024 & 0,021 & 0,020 & 0,020 & 0,016 & 0,022 \\
\hline 200 & 0,015 & 0,015 & 0,021 & 0,031 & 0,017 & 0,016 & 0,019 \\
\hline Média Geral & 0,026 & 0,022 & 0,022 & 0,033 & 0,026 & 0,016 & \\
\hline
\end{tabular}

*Significativo pelo teste $\mathrm{t}(\mathrm{P}<0,05)$.

A rápida queda do $\mathrm{pH}$ é fator desejável para que haja a interrupção das fermentações indesejáveis e consequente preservação da silagem. Segundo McDonald et al. (1991), quando há altos teores de açúcares e baixos de proteína, a estabilização da fermentação ocorre antes de 10 dias de ensilagem. Araújo et al. (2007), ao trabalharem com silagem de sorgo obtida no estádio de grãos farináceos relataram valores de $\mathrm{pH}$ entre 3,89 e 4,07 . Por conseguinte, observa-se 
que a adubação nitrogenada não elevou o $\mathrm{pH}$ das silagens para valores acima dos recomendados para uma silagem de boa qualidade.

$\mathrm{O} \mathrm{N}-\mathrm{NH}_{3}$, expresso em \% N-Total, indica a quantidade de proteína degradada durante a fase de fermentação. Verifica-se na Tabela 3 o não ajustamento na concentração de amônia, tanto para o perfil fermentativo, quanto para a adubação nitrogenada, com valor médio de $0,024 \%$. Os teores de $\mathrm{N}_{-} \mathrm{NH}_{3}$, observados neste experimento, são menores que os relatados por Araújo et al. (2007) e Ribeiro et al. (2007). Isso pode estar associado à boa fermentação do material ensilado. Segundo Muck (1996), valores de $\mathrm{pH}$ reduzidos indicam que houve maior produção de ácido láctico em detrimento dos demais ácidos orgânicos e que a proteólise foi reduzida, o que resulta também em baixa produção de $\mathrm{N}-\mathrm{NH}_{3}$.

Os teores de matéria seca (MS), proteína bruta (PB), pH e Amônia $\left(\mathrm{N}-\mathrm{NH}_{3}\right)$ não sofreram efeito da adubação nitrogenada $(\mathrm{P}>0,05)$. A matéria orgânica (MO) respondeu de forma positiva ao incremento da adubação nitrogenada, enquanto os teores de material mineral (MM) diminuíram.

Os valores médios de MS encontrados nas silagens, em resposta a todos os níveis de adubação estão dentro do padrão de fermentação de boa qualidade, cuja média geral foi de $35,41 \%$.

Os percentuais de $\mathrm{MO}$ aumentaram com o incremento da adubação nitrogenada no solo, enquanto os teores de MM diminuíram (Figura 3 e 4), tendo em vista que o aumento da MO dilui o percentual médio de $\mathrm{MM}$, sendo o valor médio total de $92,99 \%$ e $7,01 \%$ respectivamente relativo a $\mathrm{MO}$ e $\mathrm{MM}$ (Tabela 4).

Mencionado anteriormente, este aumento da MO em função da adubação nitrogenada pode estar associado ao incremento do $\mathrm{N}$ à planta, uma vez que este atua diretamente no aumento da produção de biomassa total, onde ocorre principalmente intensificação no processo de alongamento do colmo e diminuição progressiva na proporção de folhas, com consequente redução do conteúdo celular e do valor nutritivo da planta e também pela participação da panícula na produção de matéria natural.

Tabela 4. Teores médios de matéria seca (MS), matéria orgânica (MO), matéria mineral $(\mathrm{MM})$, proteína bruta (PB), $\mathrm{pH}$ e nitrogênio amoniacal $\left(\mathrm{N}-\mathrm{NH}_{3}\right)$, das silagens de sorgo em função de doses de nitrogênio $(\mathrm{X})$

\begin{tabular}{|c|c|c|c|c|c|c|c|}
\hline \multirow{2}{*}{ Variáveis } & \multicolumn{5}{|c|}{ Níveis de adubação nitrogenada $(\mathrm{kg} / \mathrm{ha})$} & \multirow{2}{*}{ Média } & \multirow{2}{*}{$\mathrm{CV}(\%)$} \\
\hline & 0 & 50 & 100 & 150 & 200 & & \\
\hline MS (\%) & 34,28 & 31,33 & 36,81 & 36,10 & 35,46 & 35,41 & 5,67 \\
\hline $\mathrm{MO}(\% \mathrm{MS})$ & 91,06 & 93,11 & 93,13 & 93,47 & 94,18 & 92,99 & 1,06 \\
\hline $\mathrm{MM}(\% \mathrm{MS})$ & 8,94 & 6,89 & 6,87 & 6,53 & 5,82 & 7,01 & 14,09 \\
\hline PB (\% MS) & 5,97 & 3,92 & 6,49 & 5,74 & 5,84 & 5,59 & 14,50 \\
\hline $\mathrm{pH}$ & 3,83 & 3,84 & 3,81 & 3,70 & 3,54 & 3,72 & 4,92 \\
\hline $\mathrm{N}-\mathrm{H}_{3}(\% \mathrm{NT})$ & 2,18 & 2,99 & 1,12 & 1,14 & 1,50 & 1,71 & 30,31 \\
\hline
\end{tabular}


Rev. Bras. Saúde Prod. Anim., Salvador, v.13, n.2, p.371-382 abr./jun., 2012 http://www.rbspa.ufba.br ISSN 15199940

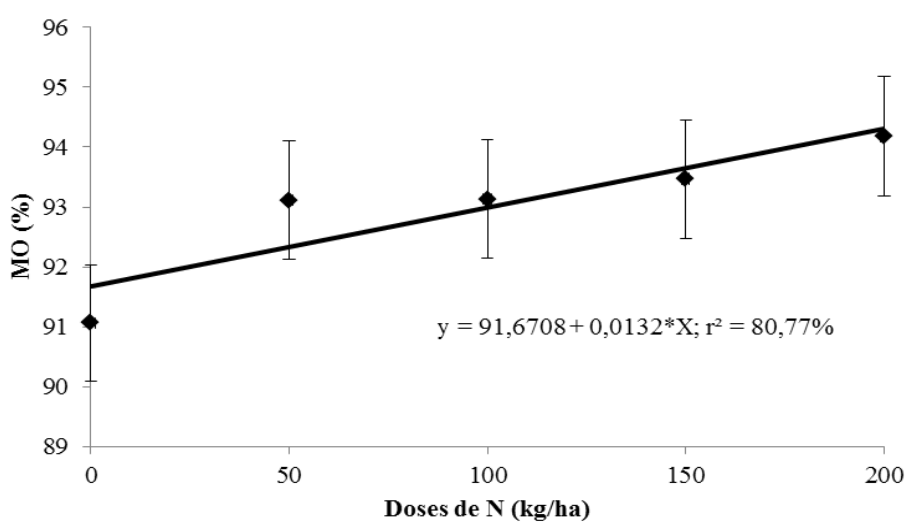

Figura 3. Variação no percentual de matéria orgânica (MO) de sorgo em função de níveis de adubação nitrogenada. As barras verticais representam o desvio padrão da média. (Cada ponto representa a média de 5 repetições)

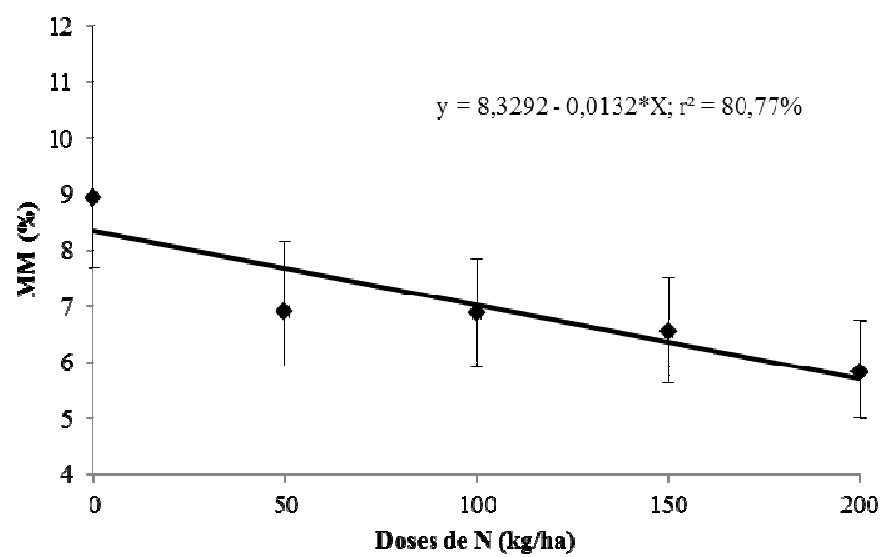

Figura 4. Variação no percentual de material mineral (MM) de sorgo em função de níveis de adubação nitrogenada. As barras verticais representam o desvio padrão da média. (Cada ponto representa a média de 5 repetições)

O teor de $\mathrm{PB}$ não diferiu entre os níveis de adubação $(\mathrm{P}>0,05)$, com valores médios variáveis de 3,92 a $6,49 \%$. Pesce et al. (2000), ao avaliarem onze genótipos de sorgo, encontraram teor médio de $8,6 \% \mathrm{~PB}$, com destaque para o híbrido BR 601 que apresentou $8,9 \%$ de PB. Não obstante, Souza et al. (2003) corroboraram esses resultados, cujos teores médio de $\mathrm{PB}$ variaram de 5,7 a $6,8 \%$ entre cinco híbridos de sorgo.
$\mathrm{O}$ valor de $\mathrm{pH}$ demonstra a acidez do material ensilado resultante do ciclo fermentativo da planta, no qual os carboidratos solúveis servem como substrato para as bactérias ácido láticas (BAL), o que eleva a produção de ácidos orgânicos, principalmente ácido lático. Consequentemente, o $\mathrm{pH}$ decresce e os micro-organismos indesejáveis são inibidos, o que garante qualidade no processo fermentativo. 
O efeito da adubação nitrogenada sobre $\mathrm{o}$ pH não foi observado, entretanto, o pH médio de 3,72 das silagens está dentro dos padrões de qualidade de silagem.

Por ser um indicador do percentual de proteína degradada durante a fermentação da silagem, o $\mathrm{N}-\mathrm{NH}_{3}$, expresso em \% $\mathrm{N}$-Total é citado como uma das principais variáveis determinantes da qualidade da fermentação. Observa-se na Tabela 2 que o $\mathrm{N}-\mathrm{NH}_{3}$ não sofreu efeito dos teores de adubo utilizado, com percentual médio de $1,71 \%$. Portanto, os resultados encontrados nesta pesquisa são inferiores aos da literatura (ARAÚJO et al., 2007; RIBEIRO et al., 2007), o que pode estar associado à boa fermentação do híbrido ensilado.
Os teores de FDN das silagens não diferiram das doses de nitrogênio utilizadas e apresentaram teor médio de $65,45 \%$ (Tabela 5). Esse valor se encontra dentro da faixa registrada pela literatura, nos híbridos de sorgo. Souza et al. (2003), ao trabalharem com cinco genótipos de sorgo, registraram valores de FDN variáveis de 60,1 a 65,0\%. Entretanto, Neumann et al. (2004), quando determinaram teores de FDN, encontraram uma variação de $65,03 \%$ a $74,23 \%$, percentuais estes superiores aos registrados por Mello et al. (2004) que encontraram variações de 59,50 a $61,67 \%$, respectivamente para híbridos Âmbar e AG-2005.

Tabela 5. Teores médios de fibra em detergente neutro (FDN), fibra em detergente ácido (FDA), lignina, celulose e hemicelulose, das silagens de sorgo em função de doses de nitrogênio (X)

\begin{tabular}{lrrrrrrr}
\hline \multirow{2}{*}{ Variáveis } & \multicolumn{5}{c}{ Níveis de adubação nitrogenada $(\mathrm{kg} / \mathrm{ha})$} & Média & \multicolumn{2}{c}{ CV } \\
\cline { 2 - 6 } & \multicolumn{1}{c}{0} & \multicolumn{1}{c}{50} & 100 & 150 & 200 & & \multicolumn{1}{c}{$\%$} \\
\hline FDN (\%) & 62,12 & 65,88 & 68,30 & 65,31 & 68,17 & 65,45 & 6,04 \\
FDA (\%) & 48,69 & 55,19 & 49,57 & 52,26 & 53,84 & 51,33 & 6,33 \\
LIGNINA & 7,14 & 9,50 & 10,73 & 10,52 & 10,72 & 9,72 & 12,56 \\
CELULOSE & 31,41 & 41,27 & 35,10 & 37,63 & 39,80 & 37,04 & 8,71 \\
HEMICELULOSE & 18,29 & 16,86 & 14,93 & 16,84 & 13,85 & 16,15 & 15,17 \\
\hline
\end{tabular}

$\overline{\mathrm{CV}}=$ coeficiente de variação.

Observa-se na Tabela 5 que a FDA e a celulose das silagens não responderam à adubação nitrogenada. Os teores médios de 51,33 e $37,04 \%$, respectivamente de FDA e celulose, são superiores aos encontrados na literatura. Neumann et al. (2002), quando avaliaram diferentes híbridos de sorgo encontraram a média de $32,69 \%$ para FDA e $26,66 \%$ para celulose. A não variação nos teores de FDN e FDA das silagens foi uma resposta expectável, tendo em vista que o aumento na adubação nitrogenada no solo sugere aumento em produtividade da planta, sem alterações nos constituintes fibrosos da mesma.

$\mathrm{Na}$ análise dos demais constituintes da parede celular na silagem, o teor de lignina respondeu de forma linear crescente ao incremento da adubação nitrogenada, com variação média de 7,14 a 10,73\% (Figura 5). 
Rev. Bras. Saúde Prod. Anim., Salvador, v.13, n.2, p.371-382 abr./jun., 2012 http://www.rbspa.ufba.br ISSN 15199940

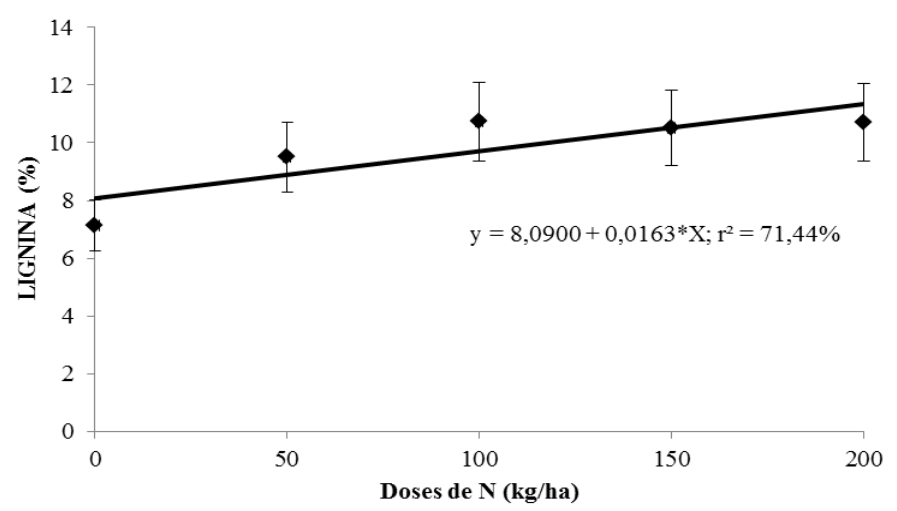

Figura 5. Variação no percentual de Lignina de sorgo em função de níveis de adubação nitrogenada. As barras verticais representam o desvio padrão da média. (Cada ponto representa a média de 5 repetições)

Esses resultados superaram os encontrados por Cândido et al. (2002), os quais obtiveram variação de 4,44 a 7,99\%. Os teores de hemicelulose reduziram linearmente com variação de $18,9 \%$ no tratamento controle e $13,85 \%$ no tratamento com $200 \mathrm{~kg} /$ ha de N (Figura $6)$.
Esses resultados são inferiores aos encontrados por Pesce et al. (2000), que ao trabalharem com o mesmo híbrido obtiveram média de $24,9 \%$ de hemicelulose. Cândido et al. (2002), ao avaliarem cinco genótipos de sorgo e quatro níveis de adubação, encontraram variação entre 19,59 a $25,48 \%$ de hemicelulose.

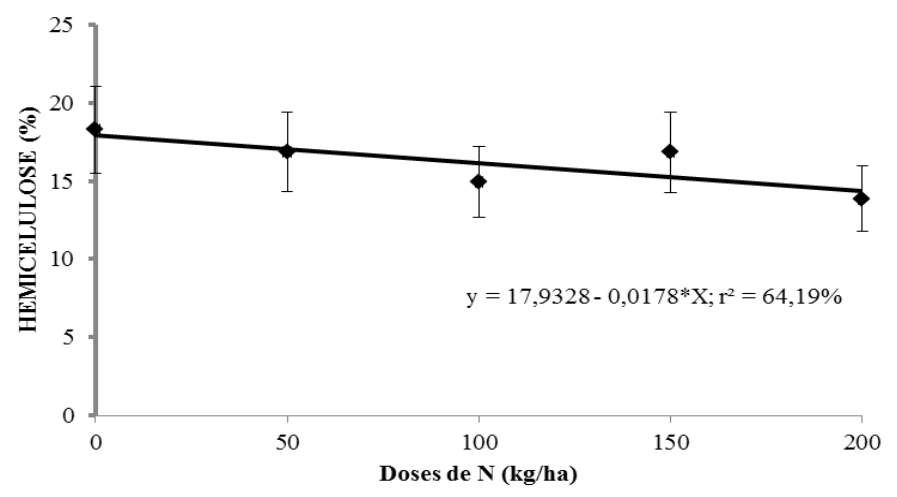

Figura 6. Variação no percentual de Hemicelulose de sorgo em função de níveis de adubação nitrogenada. As barras verticais representam o desvio padrão da média. (Cada ponto representa a média de 5 repetições)

Diante da eficácia no processo fermentativo, a utilização da adubação nitrogenada é uma prática interessante, pois aumenta a produtividade da planta sem alterar o valor nutritivo da silagem. 
$\mathrm{O}$ teor de MS e o valor de $\mathrm{pH}$ da silagem tendem a aumentar com a dose de nitrogênio no solo e com o período de fermentação. Entretanto, à medida que aumenta o tempo de fermentação da silagem, o teor de MS tende a aumentar, e o $\mathrm{pH}$ reduzir.

$\mathrm{O}$ aumento na dose de nitrogênio no solo eleva o teor de MO da silagem, mas reduz MM. Já os valores de MS, $\mathrm{PB}, \mathrm{pH}$ e amônia não sofrem alteração com esse aumento.

Dentre os constituintes da parede celular, o teor de lignina da silagem aumenta com a dose de nitrogênio, enquanto o teor de hemicelulose reduz, sem, no entanto, alterar os teores de FDN, FDA e celulose. Não obstante, o determinante na utilização da quantidade de adubo será o poder econômico do produtor. Indica-se, em função das características estudadas, a utilização de $150 \mathrm{~kg}$ de nitrogênio por hectare.

\section{REFERÊNCIAS}

ANDRADE, A.C.; FONSECA, D.M.; GOMIDE, J.A.; ALVAREZ, V, V.H.; MARTINS, C.E.; SOUZA, D.P.H. Produtividade e valor nutritivo do Capim-Elefante cv. Napier sob doses crescentes de nitrogênio e potássio.

Revista Brasileira de Zootecnia, v.29 n.6, p.1589-1595, 2000.

ARAÚJO, V.L.; RODRIGUEZ, N.M.; GONÇALVES, L.C.; RODRIGUES, J.A.S.; BORGES, I.; BORGES, A.L.C.C.; SALIBA, E.O.S. Qualidade das silagens de três híbridos de sorgo ensilados em cinco diferentes estádios de maturação. Arquivo Brasileiro de Medicina Veterinária e Zootecnia, v.59, p. 168-174, 2007.
BARROS, R.C.; ROCHA JÚNIOR.; SOUZA,V.R.; A.S.; FRANCO, M.O.; OLIVEIRA, T.S.; MENDES, G.A.; PIRES, D.A.A.; SALES, E.C.J.; CALDEIRA, L.A. Viabilidade econômica da substituição da silagem de sorgo por cana-de-açúcar ou bagaço de cana amonizado com ureia no confinamento de bovinos. Revista Brasileira de Saúde e produção Animal [Online], v.11, n.3, p.555-569 2010.

BOLSEN, K.K.; LIN, C.; BRENT, B.E. Effect of silage additives on the microbial succession and fermentation process of alfalfa and corn silages. Journal of Dairy Science, v.75, n.11, p.3066-3083, 1992.

CÂNDIDO, M.J. D.; OBEID, J.A.; PEREIRA, O.G.; CECON, P.R.; QUEIROZ, A.C.; PAULINO, M.F.; NETO, M.M.G. Valor Nutritivo de silagens de híbridos de sorgo (Sorghum bicolor (L.) Moench) sob doses crescentes de adubação. Revista Brasileira de Zootecnia, v.31, n.1, p.2029, 2002.

MARTINS, R.G.R.; GONÇALVES, L.C.; RODRIGUES, J.A.S.; RODRIGUEZ, N.M.; BORGES, I.; BORGES, A.L.C.C. Consumo e digestibilidade aparente das frações fibrosas de silagens de quatro genótipos de sorgo (Sorghum bicolor (L.) Moench) por ovinos. Arquivo Brasileiro de Medicina Veterinária e Zootecnia, v.55, n.3, p.347-350, 2003.

MELLO, R.; NÖRNBERG, J.L.; ROCHA, M.G. Potencial produtivo e qualitativo de híbridos de milho, sorgo e girassol para ensilagem. Revista Brasileira de Agrociência, v.10, n.1, p.87-95, 2004. 
Rev. Bras. Saúde Prod. Anim., Salvador, v.13, n.2, p.371-382 abr./jun., 2012 http://www.rbspa.ufba.br ISSN 15199940

McDONALD, P.; HENDERSON, A.R.; HERON, S. The biochemistry of silage. 2.ed. Marlow: Chalcombe, 1991. $340 \mathrm{p}$.

MUCK, R. Inoculant of silage and its effects on silage quality. In:

INFORMATIONAL CONFERENCE WITH DAIRY AND FORAGE INDUSTRIES, 1996. Proceedings... Madison: USDFRC, 1996. p.43-51.

NEUMANN, M.; RESTLE, J.; NÖRNBERG, J.L.; ALVES FILHO, D.C.A.; MELLO, R.O.; SOUZA, A.N.M.; PELLEGRINI, L.G. Avaliação da qualidade e do valor nutritivo da silagem de híbridos de sorgo (Sorghum bicolor (L.) Moench). Revista Brasileira de Milho e Sorgo, v.3, n.1, p.120-133, 2004.

NEUMANN, M.; RESTLE. J.; ALVES FILHO, D.C.; BERNARDES, R.A.C.; ARBOITE,M.Z.; CERDÓTES, L.; PEIXOTO, L.A.O. Avaliação de diferentes híbridos de sorgo (Sorghum bicolor, L. Moench) quanto aos componentes da planta e silagens produzidas. Revista Brasileira de

Zootecnia, v.31, n.1, p.302-312, 2002.

NUSSIO, L.G.; SHIDMIT, P.; SHORGOR, A.L.B. Cana-de-açúcar como alimento para bovinos. In: SIMPÓSIO SOBRE MANEJO ESTRATÉGICO DA PASTAGEM, 3, 2006, Viçosa, MG. Anais...Viçosa, MG: Universidade Federal de Viçosa, 2006. 432p.
OLIVEIRA, R.P.; FRANÇA, A.F.S.; MIYAGI, E.S.; SILVA, A.G.; CARVALHO, E.R.; PERÓN, H.J.M.C. Production and composition of anatomical fractions of four sorghum hybrids under nitrogen dosages. Revista Brasileira de Saúde e produção Animal [Online], v.11, n.3, p.570-580, 2010.

PESCE, D.M.C.; GONÇALVES, L.C.; RODRIGUES. J.A.S. Análise de vinte genótipos de sorgo (Sorghum bicolor (L.) Moench), de portes médio e alto, Pertencentes ao Ensaio Nacional.

Revista Brasileira de Zootecnia, v.29, n. 4 , p. $978-987,2000$

RIBEIRO, C.G.M.; GONÇALVES, L.C.; RODRIGUES, J.A.S.; RODRIGUEZ, N.M. BORGES, I.; BORGES, A.L.C.C.; SALIBA, E.O.S.; CASTRO, G.H.F.; RIBEIRO JÚNIOR, G.O. Padrão de fermentação da silagem de cinco genótipos de sorgo. Arquivo Brasileiro de Medicina Veterinária e Zootecnia, v.59, n.6, p.1531-1537, 2007.

SILVA, D.J.; QUEIROZ, A.C. Análise de alimentos: métodos químicos e biológicos. 3.ed. Viçosa, MG: Universidade Federal de Viçosa, 2002.

SOUZA, V.G.; PEREIRA, O.G.; MORAES, S.A.; GARCIA, R.; VALADARES FILHO, S.C.; ZAGO, C.P.; FREITAS, E.V.V.F. Valor nutritivo de silagens de sorgo. Revista Brasileira de Zootecnia, v.32, n.3, p.753-759, 2003.

Data de recebimento: $22 / 03 / 2011$

Data de aprovação: 29/02/2012 